\title{
Stimulation Effect of Low Level Laser Therapy on Sciatic Nerve Regeneration in Rat
}

\author{
Mohammadreza Mashhoudi Barez ${ }^{1}$, Masoud Tajziehchi ${ }^{1}$, Mohammad Hassan Heidari ${ }^{1}$, Atta Bushehri ${ }^{2}$, \\ Fariborz Moayer ${ }^{3}$, Neda Mansouri ${ }^{4}$, Niloufar Safavi Naini ${ }^{4}$, Abolfazl Movafagh ${ }^{4 *}$
}

${ }^{1}$ Cell and Molecular Biology Research Center, Department of Anatomy and Biology, Faculty of Medicine, Shahid Beheshti University of Medical Sciences, Tehran, Iran

${ }^{2}$ Genetics Research Center, University of Social Welfare and Rehabilitation Sciences, Tehran, Iran

${ }^{3}$ Department of Pathobiology, College of Veterinary Medicine, Karaj Branch, Islamic Azad University, Alborz, Iran

${ }^{4}$ Department of Medical Genetics, School of Medicine, Phytochemistry Research Center, Shahid Beheshti University of Medical Sciences, Tehran, Iran

\author{
*Correspondence to \\ Abolfazl Movafagh, Department \\ of Medical Genetics, School \\ of Medicine, Phytochemistry \\ Research Center, Shahid Beheshti \\ University of Medical Science, \\ Tehran, Iran. \\ Tel: +98 2123872572; \\ Fax: +98 2123872572; \\ Email: movafagh.a@sbmu.ac.ir
}

Published online 29 August 2017

\begin{abstract}
Introduction: Recent studies showed that low-level laser therapy (LLLT) accelerates the regeneration process of injured peripheral nerve tissue. The objective of this study was investigate the effect of LLLT $(780 \mathrm{~nm})$ on regeneration of injured right sciatic nerve of male Wistar rat.

Methods: In this research work, the effect of LLLT $(780 \mathrm{~nm})$ on the regeneration process and reconstruction of injured peripheral right side sciatic nerve was investigated. Twelve adult male Wistar rats underwent surgery in aseptic conditions under general anesthesia to induce a lesion to their right side sciatic nerve according to standard protocol. Before suturing the location, only the experimental group was treated by laser. The damaged nerve was directly irradiated with ( $2 \mathrm{~J}, 100$ $\mathrm{mW}, 40$ seconds). The irradiation procedure was terminated in 21 days with little improvement (4 J, $200 \mathrm{~mW}, 40$ seconds) across the skin surface of experimental group. Rats were selected randomly from each group to be sacrificed on different periods and histopathological examination was carried out on the extracted nerves.

Results: Significant acceleration of revascularization and angiogenesis of the injury site was observed in the experimental group. Furthermore, a reduction of hemorrhages and increase in blood supply was observed. Also, Wallerian degeneration decreased while higher axonal density compared to the control rats was observed. Moreover, the cross-section analysis of the injured area on the 14th and 21 st days as post-surgery showed that the nerve sheath diameter in the lesion area of the experimental group was reduced. While the ratio between thicknesses increased in the control group.

Conclusion: The results of the current study suggest that laser phototherapy at $780 \mathrm{~nm}$ exactly could accelerate the regeneration process of injured peripheral nerves tissue.

Keywords: Low-level laser therapy; Peripheral nerve regeneration; Wallerian degeneration; Axonal growth; Revascularization; Sciatic nerve.
\end{abstract}

\section{Introduction}

The nerve fiber or axon, is responsible for transmitting information between neuron cells. ${ }^{1}$ In humans, axons are generally on the scale of $1 \mu \mathrm{m}$ thick and some are more than $1 \mathrm{~m}$ long, ${ }^{1}$ and in the peripheral nerve system (PNS), they are either unmyelinated or myelinated by Schwann cells. ${ }^{2}$ These cells are mainly wrapped around axons and form a multi-layered sheath preparing myelin structures for axons. ${ }^{2,3}$ In case of injury, Schwann cells are activated and play a key role in nerve repair mechanism, not only concerning Wallerian degeneration and remyelination in the injured position, but also in promoting axonal growth. ${ }^{4}$ Wallerian degeneration occurs when an axon is cut or injured, in which the axon degenerates distal to the injury site. ${ }^{5-7}$ This is followed by secondary phenomena such as breakdown of the myelin sheet and activation of the Schwann and macrophages that clear up the debris. ${ }^{8,9}$ Nerve injuries are divided into 3 basic categories of neuropraxia, axonotmesis and neurotmesis based on the extent of injury, pathology and physiology according to Sir Herbert Seddon's scheme, ${ }^{5,6}$ neuropraxia, the mildest nerve injury, is a temporary loss of sensory function. ${ }^{10}$ The injured site usually fully recovers within few weeks or months, and no Wallerian degeneration occurs in this type of injury. Axonotmesis is when axons are more seriously damaged and interrupted. ${ }^{10}$ In this type of injury, the surrounding epineurium and perineurium layers remain almost intact, but there could be only partial recovery depending on the extent of injury to the axons. In addition, Wallerian degeneration may occur distal to

Please cite this article as follows: Mashhoudi Barez M, Tajziehchi M, Heidari MH, et al. Stimulation effect of low level laser therapy on sciatic nerve regeneration in rat. J Lasers Med Sci. 2017;8(Suppl 1):S32-S37. doi:10.15171/jlms.2017.s7. 
the site of injury. Neurotmesis is the most severe type of nerve injury, when complete disconnection of the nerve occurs. ${ }^{10}$ The surrounding connective tissue could also be completely damaged and surgical intervention might be required.

Use of laser in medical applications has been reported since the late $1960 \mathrm{~s},{ }^{11}$ only few years

after discovery of the first lasers examination by Ruby in 1960, and He-Ne in $1961 .^{12}$ The number of reports on the effect of low power laser and low-level laser therapy (LLLT) has gradually increased since those days. In the late 1970s, it was reported that laser energy affects the regeneration of traumatically injured peripheral nerves. ${ }^{13}$ However, most of the findings on the positive effects of phototherapy on peripheral nerve regeneration have been reported only since the late 1980s, ${ }^{14,15}$ in 1987, Rochkind et al applied low-energy He-Ne laser irradiation (LELI, 632.8 $\mathrm{nm}, 10 \mathrm{~J} / \mathrm{cm}^{2}$, continuous) on both intact and severely injured peripheral nerves in rats for 20 consecutive days and reported promising electrophysiological and morphological effects. ${ }^{16}$ This was followed by a report on decrease in formation of scar tissue at the site of injury ${ }^{17}$ and acceleration of the regeneration process of severely injured sciatic nerve and spinal cord. ${ }^{18}$ Few years later, the same approach was carried out on crushed peroneal nerve of rabbit for 15 consecutive days, obtaining similar results. ${ }^{19}$ Since then, many other studies on the effect of different wavelengths of LLLT on slight and mild peripheral nerve lesion have been reported. ${ }^{14,20-25}$ In addition, combination of laser therapy with entubulation to reconstruct massive segmental loss of peripheral nerve has shown very promising outcomes. ${ }^{26-28}$ Most reports on the effect of LLLT on PNS injury are in cases of axonotmesis. ${ }^{13-15,18-21,25,29-32}$ However, promising results have been obtained in severe cases of neurotmesis when LLLT is used in combination with or Gore-Tex tubes. ${ }^{27}$

The cutaneous branch consisted of 400 myelinated and 1800 unmyelinated afferent axons. The entire sciatic nerve at midthigh is composed of about 27000 axons; $6 \%$ are myelinated motor axons, $23 \%$ and $48 \%$ are myelinated and unmyelinated sensory axons in rat, respectively. ${ }^{33}$

The aim of this study was investigate the effect of LLLT $(780 \mathrm{~nm})$ on regeneration of the injured right sciatic nerve of male Wistar rat.

\section{Materials and Methods}

Animal preparation and surgical procedure

Twelve adult male Wistar rats (250-300 g) were randomly divided into 2 similar groups (6 for experimental and 6 for control groups). All rats were anesthetized by injecting a mixture of $5 \mathrm{mg} / \mathrm{kg}$ xylazine (Rampun ${ }^{\circledR}$, Bayer AG, Germany) with $100 \mathrm{mg} / \mathrm{kg}$ ketamine (Ketalar ${ }^{\circledR}$, Parke Davis, Germany) administered intramuscularly, and later underwent an operation; first of all, lateral aspect of the right leg was located, and then biceps femoris and semimembranosus were separated in order to expose the sciatic nerve (peroneal). Next, the sciatic nerve was crushed using a microsurgical blade. The crushed site was set up like a triangle on the border of the nerve. To close the surgery lesion a chromic catgut USP 4-0 and a silk suture USP 3-0 (KRUUSE, Denmark) were used in 2 layers. The experimental group did not receive any antibiotic after the surgery, while the control group received penicillin (1500 IU/kg of body weight) for 7 consecutive days.

\section{Low-Level Laser Therapy}

Right after creating crush injury to their sciatic nerves, the rats that were assigned to the experimental group were directly treated by low-power laser irradiation (Table 1). The irradiation of this group continued transcutaneously until the day before sacrifice using GaAlAs + GaAlInP diode laser system (RJ Laser GmbH, Germany) for 40 seconds. The instrument consisted of 12 diodes and pulse repetition rate of $292 \mathrm{~Hz}$ and $1168 \mathrm{~Hz}$ with 2 wavelengths of $655 \mathrm{~nm}$ and $785 \mathrm{~nm}$ (impulsive). The power was set at $100 \mathrm{~mW}$ for the operation day and $200 \mathrm{~mW}$ for the remaining days. On the day of operation, the energy of the laser was $2 \mathrm{~J}$, but for the remaining days it was kept at $4 \mathrm{~J}$.

\section{Collecting Specimens}

On the 1 st, $3 \mathrm{rd}, 5$ th, 7 th, 14 th and 21 st days after surgery, the rats were sacrificed with anesthesia and transfused with $10 \%$ formalin through the left heart ventricle. The samples of the right sciatic nerves were excised and sent for histopathological examination.

\section{Histopathological Preparing}

All tissue samples were fixed in 10\% neutral buffered formalin and embedded in paraffin cub. Next, they were stained with hematoxylin and eosin (H\&E) and then the histopathological slides were examined by a light microscope.

\section{Results}

Laser Therapy Accelerates Revascularization

The effect of laser therapy on revascularization and angiogenesis was studied by endothelial cell proliferation of the treated region (Figure 1A, 1B). Because of LLLT, no antibiotic was used for the experimental group and fortunately there was no infection to report on the injury site.

Histopathological examination of the specimens obtained from the experimental group three days after the surgery showed significant acceleration in revascularization compared to those obtained from the control rats.

\section{Reduction of Wallerian Degeneration}

In addition, Wallerian degeneration was quite apparent in the control rats (Figure 2A). But this was postponed in the experimental group (Figure $2 \mathrm{~B}$ ) while the quantity of Schwann cells in this group increased as well. It should also be added that the regeneration of the injured nerve began on the day third post-surgery in comparison to the control group. 
Table 1. Laser Irradiation Data of the Control and Experimental Groups on the Day of Operation and Postsurgery

\begin{tabular}{|c|c|c|c|c|c|c|c|}
\hline \multicolumn{2}{|c|}{ RS } & \multirow{2}{*}{ TS No. } & \multirow{2}{*}{ Specimen No. } & \multicolumn{3}{|c|}{ LP } & \multirow{2}{*}{ Laser irradiation Method } \\
\hline $\mathbf{L}$ & C & & & E. (J) & P. $(\mathrm{mW})$ & T. (s) & \\
\hline 6 & 6 & 0 & - & 2 & 100 & 40 & Direct to the nerve injury (after created sciatic injury) \\
\hline 6 & 6 & 1 & - & 4 & 200 & 40 & Contact (on the skin of injury area) \\
\hline 5 & 5 & 2 & $1^{\text {st }} \mathrm{Sp}$. & 4 & 200 & 40 & Contact (on the skin of injury area) \\
\hline 5 & 5 & 3 & - & 4 & 200 & 40 & Contact (on the skin of injury area) \\
\hline 4 & 4 & 4 & $2^{\text {st }} \mathrm{Sp}$ & 4 & 200 & 40 & Contact (on the skin of injury area) \\
\hline 4 & 4 & 5 & - & 4 & 200 & 40 & Contact (on the skin of injury area) \\
\hline 3 & 3 & 6 & $3^{\text {rd }} \mathrm{Sp}$. & 4 & 200 & 40 & Contact (on the skin of injury area) \\
\hline 3 & 3 & 7 & - & 4 & 200 & 40 & Contact (on the skin of injury area) \\
\hline 2 & 2 & 8 & $4^{\text {th }} \mathrm{Sp}$. & 4 & 200 & 40 & Contact (on the skin of injury area) \\
\hline 2 & 2 & 9 & - & 4 & 200 & 40 & Contact (on the skin of injury area) \\
\hline 2 & 2 & 10 & - & 4 & 200 & 40 & Contact (on the skin of injury area) \\
\hline 2 & 2 & 11 & - & 4 & 200 & 40 & Contact (on the skin of injury area) \\
\hline 2 & 2 & 12 & - & 4 & 200 & 40 & Contact (on the skin of injury area) \\
\hline 2 & 2 & 13 & - & 4 & 200 & 40 & Contact (on the skin of injury area) \\
\hline 2 & 2 & 14 & - & 4 & 200 & 40 & Contact (on the skin of injury area) \\
\hline 1 & 1 & 15 & $5^{\text {th }} \mathrm{Sp}$. & 4 & 200 & 40 & Contact (on the skin of injury area) \\
\hline 1 & 1 & 16 & - & 4 & 200 & 40 & Contact (on the skin of injury area) \\
\hline 1 & 1 & 17 & - & 4 & 200 & 40 & Contact (on the skin of injury area) \\
\hline 1 & 1 & 18 & - & 4 & 200 & 40 & Contact (on the skin of injury area) \\
\hline 1 & 1 & 19 & - & 4 & 200 & 40 & Contact (on the skin of injury area) \\
\hline 1 & 1 & 20 & - & 4 & 200 & 40 & Contact (on the skin of injury area) \\
\hline 1 & 1 & 21 & - & 4 & 200 & 40 & Contact (on the skin of injury area) \\
\hline- & - & - & $6^{\text {th }} \mathrm{Sp}$. & - & - & - & - \\
\hline
\end{tabular}

Abbreviations: RS, rats specimen; TS, therapy session; E, energy; P, power; T, time; LP, laser parameter; C, control, L, laser.
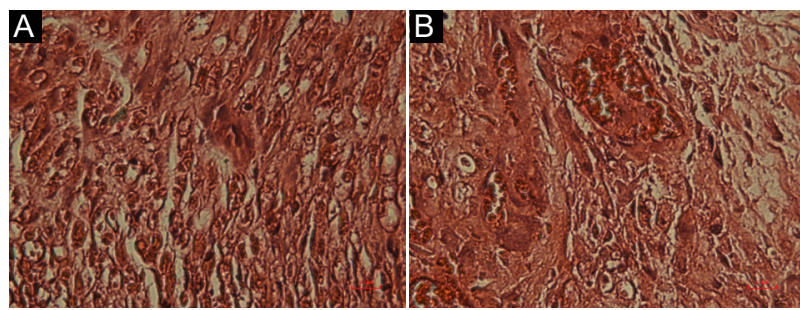

Figure 1. Histopathological Comparison Between Control (A) and Experimental (B) Groups 3 Days After Laser Therapy.

Note the significant revascularization in the experimental group and hemorrhage in the control group. Ellipses indicate revascularization and the bar indicates $20 \mu \mathrm{m}$.

Increase in axonal density after LLLT

Laser irradiation reduced the formation of scar tissue in the experimental group (data not shown). It also improved the quality and increased quantity of axons in this group (Figure 3).

Comparison Between Nerve Fiber Diameters in Presence or Absence of LLLT

Histopathological examination of the diameter of the nerve fibers on 14th and 21st days post-surgery showed that the rate of healing, growth and nerve repair in the experimental group in comparison to the control group was faster (Figure 4A, B, 5A, B). By comparing the nerve initial diameter to the nerve diameter (Table 2) on the 14 th and 21st days, it was found that the ratio between the thicknesses increased in the control group (2.49 on day
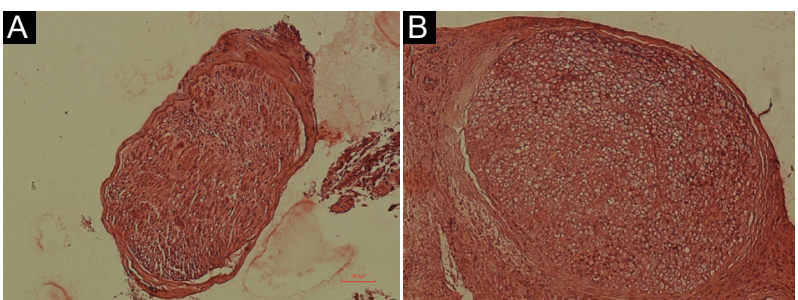

Figure 2. Histopathological Comparison Between Control (A) and Experimental (B) Groups 3 Days After Laser Therapy.

The cross section images show Wallerian degeneration in the control group and increase in the quantity of Schwann cells in the experimental group. The bar indicates $100 \mu \mathrm{m}$.

14th and 2.79 on day 21 st), while the laser-treated group had lower thickness ratio in either of the days ( 1.85 on day 14 th and 1.55 on day 21 st).

\section{Discussion}

In this research work, firstly, the effect of LLLT on revascularization and angiogenesis of injured right sciatic nerve of rat was investigated. It has been previously shown that laser therapy can increase blood flow, revascularization ${ }^{34-36}$ and generate healing to an injured area. ${ }^{37}$ This is believed to be the result of release of angiogenic factors such as vascular endothelial growth factor (VEGF), fibroblast growth factor (FGF), type I collagen (Col-I) and inducible nitric oxide synthase (iNOS) that playkey roles in angiogenesis, ${ }^{38-41}$ subsequently assisting and accelerating nerve regeneration. Our 


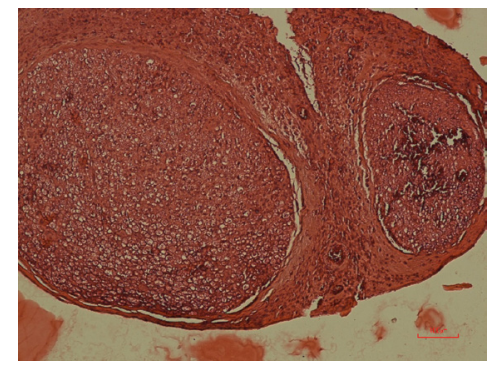

Figure 3. Increase of Axonal Density in the Experimental Group After LLLT. The bar indicates $100 \mu \mathrm{m}$.
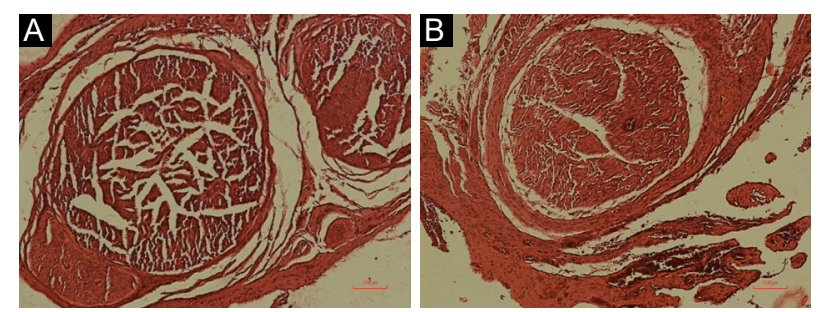

Figure 4. Comparison Between Diameters of the Nerve Fibers in Control (A) and Experimental (B) Groups on Day 14th. The bar indicates $100 \mu \mathrm{m}$.
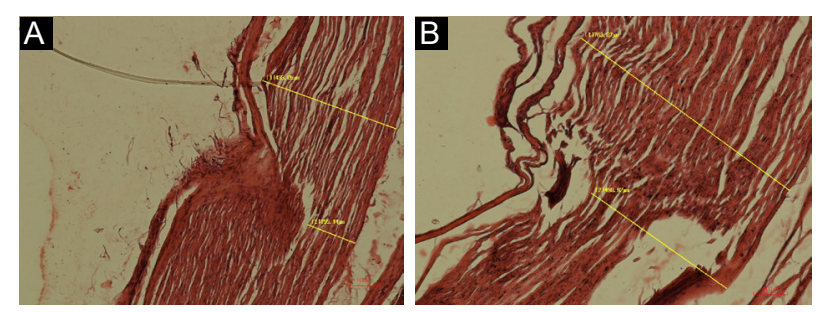

Figure 5. Comparison Between the Initial Diameters to the Nerve Diameters in Control (A) and Experimental (B) Groups on Day 21st.

Note the successful regeneration in the experimental group after 21 days. The bar indicates $100 \mu \mathrm{m}$.

histopathological examination showed that LLLT (780 $\mathrm{nm}$ ) accelerated revascularization and angiogenesis in the experimental group (Figure 1). There were also many hemorrhages in the control group, while the quantity of hemorrhages was far less in the experimental group.

Wallerian degeneration normally starts 24-36 hours after nerve injury in both PNS and central nervous system (CNS). ${ }^{8,9,42}$ The main effector cells in Wallerian degeneration are hematogenous phagocytes, ${ }^{43}$ with Schwann cells and macrophages also participating in myelin removal to phagocytize the debris left from the breakdown of myelin sheath. Our results showed significant decrease in Wallerian degeneration after LLLT in the experimental group (Figure 2), further approving that laser therapy affects axonal growth and regeneration (Figure 3). LLLT reduced the presence of inflammatory cells in the experimental group in comparison to the control group. Moreover, the quantity of healthy Schwann cells in the injured area increased (Figure 2B), showing that they really play an important role in reconstruction and restoration of the injured peripheral nerve to its original shape. The crushed sciatic nerve could reach the regeneration phase as early as the third day post-surgery in comparison to the control group, showing the protocol used in this study was certainly effective.

LLLT's mechanism of action involves mitochondria and its products. ${ }^{12}$ Cellular respiration is upregulated when mitochondria are exposed to different kinds of illumination such as $\mathrm{He}-\mathrm{Ne}$ laser irradiation ${ }^{12}$ and therefore these organelles play a central role in absorbing light and mediating the subsequent pathways during LLLT. Such an effect could have occurred in Schwann and/ or other cells surrounding the crushed site to accelerate the healing process since laser irradiated experimental rats regenerated healthy axons and tissue (Figures 2 and 3 ), but this would need more data to draw firm results.

In addition, it has been reported that continuous lowpower He-Ne laser irradiation can decrease formation of scar tissue in peripheral nerve injury. ${ }^{44}$ In this investigation, the diameter of the laser irradiated injured nerve was decreased in comparison to the control rats exhibited in Figure 4. Moreover, the diameter of the nerve fiber and regular myelin layers are also indicators of effective regeneration of LLLT. On days 14th and 21st, the ratio between the initial diameter of the nerve fiber (D1) to its actual diameter (D2) was measured (Table 2) in either one of the groups (Figure 5). The nerve growth and regeneration resulted in a lower $\mathrm{D} 1 / \mathrm{D} 2$ ratio in the experimental group.

Detail analysis of LLLT could also be due to the fact that nerve growth factor (NGF) synthesis can be regulated by low-level irradiation. ${ }^{45}$ Nerve growth factor is required for the survival of developing sympathetic and sensory neurons, especially when the nerve fiber is injured and neurons need to be protected from apoptosis, ${ }^{46}$

Table 2. Comparison Between the Thickness of Nerve Fibers in Experimental and Control Rats After Laser Therapy on Days 14 th and $21 \mathrm{st}^{\mathrm{a}}$

\begin{tabular}{|c|c|c|c|c|}
\hline \multirow{3}{*}{ Control group } & \multicolumn{2}{|c|}{$14^{\text {th }}$ Day } & \multicolumn{2}{|c|}{$21^{\text {st }}$ Day } \\
\hline & $\mathrm{D} 1=400.02$ & $\mathrm{D} 2=160.03$ & $\mathrm{D} 1=433.05$ & $\mathrm{D} 2=155.14$ \\
\hline & \multicolumn{2}{|c|}{$\mathrm{Rc}=2.49$} & \multicolumn{2}{|c|}{$\mathrm{Rc}=2.79$} \\
\hline \multirow{2}{*}{ Experimental group } & $\mathrm{D} 1=390.03$ & $\mathrm{D} 2=210.01$ & $\mathrm{D} 1=763.87$ & $\mathrm{D} 2=490.92$ \\
\hline & \multicolumn{2}{|c|}{$\mathrm{Re}=1.85$} & \multicolumn{2}{|c|}{$\mathrm{Re}=1.55$} \\
\hline
\end{tabular}

a The D1/D2 ratio in the control group was less than the experimental group, indicating effective regeneration.

$\mathrm{D}_{1}$ : initial nerve diameter, $\mathrm{D}_{2}$ : nerve diameter after restoration, Rc: Ratio control, Re: Ratio exanimate and R: D1/D2. 
a biochemical process that results in change of cell morphology and leads to death. Further research will be needed in the future to study such factors.

\section{Conclusion}

The results of this study suggest that the immediate usage of LLLT $(780 \mathrm{~nm}$ ) right after operation, improves recovery and positively accelerates peripheral nerve regeneration.

\section{Ethical Considerations}

The Medical Ethics Committees of Cell and Molecular Biology Research Center, Department of Anatomy and Biology, School of Medicine, Shahid Beheshti University of Medical sciences, Iran approved the study protocol.

\section{Conflict of Interests}

The authors report no conflict of interest.

\section{References}

1. Akgul T, Gulsoy M, Gulcur HO. Effects of early and delayed laser application on nerve regeneration. Lasers Med Sci. 2014;29(1):351-357. doi:10.1007/s10103-013-1355-9.

2. Beigom Taheri J, Bagheri F, Mojahedi M, et al. Comparison of the effect of low-level laser and phenytoin therapy on skin wound healing in rats. J Lasers Med Sci. 2015;6(3):124128. doi:10.15171/jlms.2015.06.

3. Bhatheja K, Field J. Schwann cells: origins and role in axonal maintenance and regeneration. Int J Biochem Cell Biol. 2006;38(12):1995-1999. doi:10.1016/j.biocel.2006.05.007

4. Liu H, Lv P, Zhu Y, et al. Salidroside promotes peripheral nerve regeneration based on tissue engineering strategy using Schwann cells and PLGA: in vitro and in vivo. Sci Rep. 2017;7:39869. doi:10.1038/srep39869.

5. Etemadi A, Sadeghi M, Dadjou MH. The Effects of Low Level 660nm Laser Irradiation on Pain and Teeth Hypersensitivity after Periodontal Surgery. J Lasers Med Sci. 2011;2:103-108.

6. Hasamnis A, Mohanty B, Muralikrishn. Evaluation of wound healing effect of topical phenytoin on excisional wound in albino rats. J Young Pharm. 2010;2(1):59-62. doi:10.4103/0975-1483.62215.

7. Huang Z, Ma J, Chen J, Shen B, Pei F, Kraus VB. The effectiveness of low-level laser therapy for nonspecific chronic low back pain: a systematic review and metaanalysis. Arthritis Res Ther. 2015;17:360. doi:10.1186/ s13075-015-0882-0.

8. Coleman MP, Conforti L, Buckmaster EA, et al. An 85-kb tandem triplication in the slow Wallerian degeneration (Wlds) mouse. Proc Natl Acad Sci USA. 1998;95(17):99859990.

9. Beuche W, Friede RL. The role of non-resident cells in Wallerian degeneration. J Neurocytol. 1984;13(5):767-796.

10. Burnett MG, Zager EL. Pathophysiology of peripheral nerve injury: a brief review. Neurosurg Focus. 2004;16(5):E1.

11. Mester E, Szende B, Gartner P. The effect of laser beams on the growth of hair in mice. Radiobiol Radiother (Berl). 1968;9(5):621-626.

12. Hashmi JT, Huang YY, Osmani BZ, Sharma SK, Naeser MA, Hamblin MR. Role of low-level laser therapy in neurorehabilitation. PM R. 2010;2(12 Suppl 2):S292-S305. doi:10.1016/j.pmrj.2010.10.013.
13. Rochkind S. Stimulation effect of laser energy on the regeneration of traumatically injured peripheral nerves. Morphogen Regen. 1978;83:25-27.

14. Gigo-Benato D, Geuna S, Rochkind S. Phototherapy for enhancing peripheral nerve repair: a review of the literature. Muscle Nerve. 2005;31(6):694-701.

15. Rochkind S. Phototherapy in peripheral nerve regeneration: From basic science to clinical study. Neurosurg Focus. 2009;26(2):E8. doi:10.3171/FOC.2009.26.2.E8.

16. Rochkind S, Barrnea L, Razon N, Bartal A, Schwartz M. Stimulatory effect of $\mathrm{He}-\mathrm{Ne}$ low dose laser on injured sciatic nerves of rats. Neurosurgery. 1987;20(6):843-847.

17. Rochkind S, Nissan M, Barr-Nea L, Razon N, Schwartz $\mathrm{M}, \mathrm{Bartal} \mathrm{A}$. Response of peripheral nerve to He-Ne laser: experimental studies. Lasers Surg Med. 1987;7(5):441-443.

18. Rochkind S, Barr-Nea L, Bartal A, Nissan M, Lubart R, Razon N. New methods of treatment of severely injured sciatic nerve and spinal cord. An experimental study. Acta Neurochir Suppl (Wien). 1988;43:91-93.

19. Hamilton GF, Robinson TK, Ray RH. The effects of heliumneon laser upon regeneration of the crushed peroneal nerve. J Orthop Sports Phys Ther. 1992;15(5):209-214.

20. Anders JJ, Borke RC, Woolery SK, Van de Merwe WP. Low power laser irradiation alters the rate of regeneration of the rat facial nerve. Lasers Surg Med. 1993;13(1):72-82.

21. Khullar SM, Brodin P, Messelt EB, Haanaes HR. The effects of low level laser treatment on recovery of nerve conduction and motor function after compression injury in the rat sciatic nerve. Eur J Oral Sci. 1995;103(5):299-305.

22. Bagis S, Comelekoglu U, Coskun B, et al. No effect of GAAS $(904 \mathrm{~nm})$ laser irradiation on the intact skin of the injured rat sciatic nerve. Lasers Med Sci. 2003;18(2):83-88.

23. Chen YS, Hsu SF, Chiu CW, et al. Effect of low-power pulsed laser on peripheral nerve regeneration in rats. Microsurgery. 2005; 25(1):83-89.

24. Anders JJ, Geuna S, Rochkind S. Phototherapy promotes regeneration and functional recovery of injured peripheral nerve. Neurol Res. 2004;26(2):233-239.

25. Barbosa RI, Marcolino AM, de Jesus Guirro RR, Mazzer N, Barbieri CH, de Cássia Registro Fonseca M. Comparative effects of wavelengths of low-power laser in regeneration of sciatic nerve in rats following crushing lesion. Lasers Med Sci. 2010;25(3):423-430. doi:10.1007/s10103-009-0750-8.

26. Dellon AL, Mackinnon SE. An alternative to the classical nerve graft for the management of the short nerve gap. Plast Reconstr Surg. 1988;82(5):849.

27. Miloro M, Halkias LE, Mallery S, Travers S, Rashid RG. Low-level laser effect on neural regeneration in Gore-Tex tubes. Oral Surg Oral Med Oral Pathol Oral Radiol Endod. 2002;3(1):27-34.

28. Rochkind S, Drory V, Alon M, Nissan M, Ouaknine GE. Laser phototherapy $(780 \mathrm{~nm})$, a new modality in treatment of long-term incomplete peripheral nerve injury: a randomized double-blind placebo-controlled study. Photomed Laser Surg. 2007;25(5):436-442.

29. Midamba ED, Haanaes HR. Low reactive-level 830nm GaAlAs diode laser therapy (LLLT) successfully accelerates regeneration of peripheral nerves in human. Laser Ther. 1993:5:125-129.

30. Basford JR, Hallman HO, Matsumoto JY, Moyer SK, Buss JM, Baxter GD. Effects of $830 \mathrm{~nm}$ continuous wave laser diode irradiation on median nerve function in normal subjects. Lasers Surg Med. 1993;13(6):597-604. 
31. Rochkind S, Shainberg A. Muscle response to complete peripheral nerve injury: changes of acetylcholine receptor and creatine kinase activity over time. J Reconstr Microsurg. 2017;33(5):352-357.

32. Rochkind S, Leider-Trejo L, Nissan M, Shamir MH, Kharenko O, Alon M. Efficacy of 780-nm laser phototherapy on peripheral nerve regeneration after neurotube reconstruction procedure (double-blind randomized study). Photomed Laser Surg. 2007;25(3):137143.

33. Schmalbruch H. Fiber composition of the rat sciatic nerve. Anat Rec. 1986;215(1):71-81.

34. Mirhoseini M, Cayton MM. Revascularization of the heart by laser. J Microsurg. 1981;2(4):253-260.

35. Schindl A, Merwald H, Schindl L, Kaun C, Wojta J. Direct stimulatory effect of lowintensity $670 \mathrm{~nm}$ laser irradiation on human endothelial cell proliferation. Br J Dermatol. 2000;148(2):334-336.

36. McGillion M, Cook A, Victor JC, et al. Effectiveness of percutaneous laser revascularization therapy for refractory angina. Vasc Health Risk Manag. 2010;6:735-747.

37. Posten W, Wrone DA, Dover JS, Arndt KA, Silapunt S, Alam M. Low-level laser therapy for wound healing: mechanism and efficacy. Dermatol Surg. 2010;31(3):334-340.

38. Basso FG, Oliveira CF, Kurachi C, Hebling J, Costa CA. Biostimulatory effect of lowlevel laser therapy on keratinocytes in vitro. Lasers Med Sci. 2013;28(2):367-374. doi:10.1007/s10103-012-1057-8.

39. Dourado DM, Favero S, Matias R, Carvalho Pde T, da. Cruz-Hofling MA. Low-level laser therapy promotes vascular endothelial growth factor receptor-1 expression in endothelial and nonendothelial cells of mice gastrocnemius exposed to snake venom. Photochem Photobiol. 2011;87(2):418-426. doi:10.1111/j.1751- 1097.2010.00878.x.

40. Tuby H, Maltz L, Oron U. Modulations of VEGF and iNOS in the rat heart by low level laser therapy are associated with cardioprotection and enhanced angiogenesis. Lasers Surg Med. 2006;38(7):682-688

41. Safavi SM, Kazemi B, Esmaeili M, Fallah A, Modarresi A, Mir M. Effects of lowlevel He-Ne laser irradiation on the gene expression of IL-1beta, TNF-alpha, IFN-gamma, TGFbeta, bFGF, and PDGF in rat's gingiva. J Lasers Med Sci. 2008; 23(3):331-335. doi:10.1007/s10103-007-0491-5.

42. Waller A. Experiments on the section of the glossopharyngeal and hypoglossal nerves of the frog, and observations of the alterations produced thereby in the structure of their primitive fibres. Phil Trans Roy Soc London. 1850;140:423-429.

43. Müller M, Leonhard C, Krauthausen M, Wacker K, Kiefer $\mathrm{R}$. On the longevity of resident endoneurial macrophages in the peripheral nervous system: a study of physiological macrophage turnover in bone marrow chimeric mice. $J$ Peripher Nerv Syst. 2010;15:357-65. doi:10.1111/j.15298027.2010.00295.x.

44. Rochkind S. Phototherapy in peripheral nerve injury for muscle preservation and nerve regeneration. Photomed Laser Surg. 2009;27(2):219-220. doi:10.1016/S00747742(09)87025-6

45. Schwartz F, Brodie C, Appel E, Kazimirsky G, Shainberg A. Effect of helium/neon laser irradiation on nerve growth factor synthesis and secretion in skeletal muscle cultures. $J$ Photochem Photobiol B. 2002;66(3):195-200.

46. Freeman RS, Burch RL, Crowder RJ, et al. NGF deprivationinduced gene expression: after ten years, where do we stand? Prog Brain Res. 2004;146:111-126. doi:10.1016/ S0079-6123(03)46008-1. 